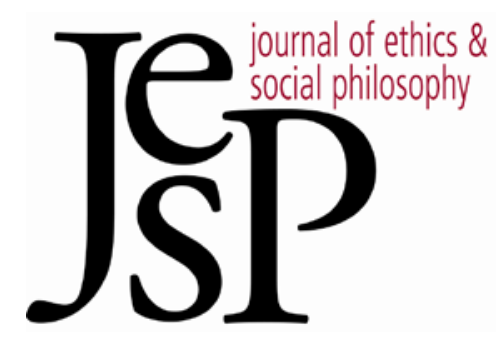

\title{
Normative Source and Extensional Adequacy
}

\author{
BY JEFF BEHRENDS
}

JoURNAL OF ETHICS \&SOCIAL PHILOSOPHY

Vol. 10, No. 3 | August 2016 URL: WWW.JESP.ORG

COPYRIGHT (C) JEFF BEHRENDS 2016 


\title{
Normative Source and Extensional Adequacy
}

\author{
Jeff Behrends
}

\section{$\mathrm{T}$} AKE SOURCE INTERNALISM TO BE THE POSITION that all facts that constitute objective, practical reasons do so in virtue of a relation in which they stand to the pro-attitudes of agents, or the proattitudes that agents would have under some specified set of circumstances. For instance, on such a view, some fact might count as a reason for me to act because it is part of what explains why so acting would get me closer to the satisfaction of one of my desires. ${ }^{1}$ This kind of internalist view is typically contrasted with the position that practical normativity is never grounded in this way: Source Externalism.2

Source Internalism is typically thought to have the consequence that the reasons any agent has depend on the details of her mental states, such that if she had different pro-attitudes then she would have different reasons. ${ }^{3}$ Many have found that consequence objectionable, on the grounds that there are some practical reasons that should not be held hostage to the psychological details of agents in the way that Source Internalism seems to imply that all are. Source Internalists, so the objection goes, cannot account for all of the reasons that there are. This kind of difficulty is what Mark Schroeder calls the Too Few Reasons objection, and is a species of the more general alleged difficulty that Source Internalism is extensionally inadequate - that it does not render the correct verdicts about what reasons there are in important cases. ${ }^{4}$

My project in this paper is motivated by an interest in that alleged inadequacy. The question that I wish to consider is this: does Source Internalism, despite initial appearances to the contrary, have the resources to accommodate our pre-theoretical intuitions about the kinds of cases its detractors utilize in their objections? I organize the bulk of my discussion around Derek Parfit's All or None Argument.5 It is one of several arguments that Parfit offers in an attempt to undermine Source Internalism, and it proceeds by demonstrating that an internalist picture yields unsavory results about certain kinds

\footnotetext{
1 Schroeder (2007).

2 To the best of my knowledge, the terms "Source Internalism," "Source Externalism" and "Source Hybridism" are due to Ruth Chang. The characterization of Source Externalism may be dissatisfying to some, since externalisms are often defined simply as the negation of their corresponding internalisms. But I follow Chang here, and think that her usage is helpful, partially because externalists in this context typically have been of the extreme sort described in the main text. If this taxonomy is offensive to you, however, you can think of the relevant distinctions as being among internalism, extreme externalism and a more moderate externalism.

${ }^{3}$ Here, and throughout, I will ignore any distinction between an agent having a reason, and there being a reason for that agent. Throughout, when I say that an agent has a reason to $\Phi, \mathrm{I}$ mean only that there exists some reason for her to $\Phi$.

4 Schroeder (2007: 103-22).

5 Parfit (2011: 90).
} 
of cases. However, the argument has a somewhat surprising conclusion. Rather than aiming explicitly at the denial of internalism, it concludes with the logically stronger position that no practical reasons could be grounded in the way that internalists believe that all are.

I argue that Parfit has overstated his case, and that understanding how he has done so may have an important upshot in the debate concerning the source of practical normativity. In what follows, I agree with Parfit that Source Internalism cannot vindicate our commonly held intuitions about the cases he imagines. Fully demonstrating that failure requires showing that the most recent and sophisticated attempts to defend internalism are unsuccessful. However, I also argue that Parfit's argument nevertheless fails to establish its ambitious conclusion. In so doing, I draw attention to the possibility of an alternative to both Source Internalism and Source Externalism: Source Hybridism. ${ }^{6}$ If the arguments of this paper are successful, I will have shown that Source Hybridism enjoys at least one theoretical advantage over Source Internalism - not a decisive result, to be sure, but an important one for the project of determining which theory of the source of practical normativity enjoys most theoretical support, all things considered.

\section{The All or None Argument}

Here is Parfit's All or None Argument in its entirety:

(1) If we have desire-based reasons for acting, all that would matter is whether some act would fulfill the telic desires that we now have after ideal deliberation. It would be irrelevant what we want, or would be trying to achieve.

(2) Therefore, either all such desires give us reasons, or none of them do.

(3) If all such desires gave us reasons, our desires could give us decisive reasons to cause ourselves to be in agony for its own sake, to waste our lives, and to try to achieve countless other bad or worthless aims.

(4) We could not have such reasons.

(5) Therefore, none of these desires gives us any reason. We have no such desirebased reason to have any desire, or to act in any way. ${ }^{7}$

\footnotetext{
${ }^{6} \mathrm{I}$ am not alone in suggesting that a hybrid approach to the grounding of practical normativity offers promising payoffs, though I am, so far as I know, very nearly alone. In a series of recent papers, Ruth Chang has defended a position that she calls bybrid voluntarism, which is a particular instance of Source Hybridism. The argument I offer here operates at a higher level of generality than many of Chang's, and does not lend special support to her view; there are good reasons to support Source Hybridism that are not also reasons to support hybrid voluntarism in particular. For the most relevant of Chang's writings, see her (2009), (2012a), (2012b) and (2013). Sarah Paul and Jennifer Morton (2014) have also expressed some tentative support for a hybrid approach, and I have defended the view in my (2015). 7 Apart from adding the numbers, I quote the argument directly from Parfit (2011: 90).
} 
I will soon begin an assessment of this argument, but, before I do, some preliminary comments concerning Parfit's understanding of internalism are in order. Parfit makes mention here of the "telic desires that we now have after ideal deliberation." Telic desires are those the objects of which we desire for their own sakes. ${ }^{8}$ Parfit argues that any plausible version of Source Internalism must have it that some, but not all, of our desires are the kinds in which reasons can be grounded. ${ }^{9}$ He concludes that the best candidates for reasongenerating desires are the telic desires that we would have after ideal deliberation. ${ }^{10}$ I will have more to say about this restriction when I consider premise (1) in more detail.

It will be helpful also to look at an example of a case that is supposed to motivate premises (3) and (4). Here is a case from Parfit's own discussion:

Case Two. I want to have some future period of agony. I am not a masochist, who wants this pain as a means to sexual pleasure. Nor am I a repentant sinner, who wants this pain as deserved punishment for my sins. Nor do I have any other present desire or aim that would be fulfilled by my future agony. I want this agony as an end, or for its own sake. I have no other present desire or aim whose fulfillment would be prevented either by this agony, or by my having my desire to have this agony. After ideal deliberation, I decide to cause myself to have this future agony, if I can, to the exclusion of any other alternative action open to me. ${ }^{11}$

Parfit's worry is that, if Source Internalism is true, then the agent in Case Two has decisive reason to cause herself to be in agony for its own sake, regardless of what else that agent could otherwise do. Since that is implausible, he contends, we ought to reject Source Internalism. Again, there will be more to say on this topic when I consider the premises in more detail. In short, though, the appeal to Case Two explains Parfit's support for both premises (3) and (4).

The inference from premises (2), (3) and (4) to the conclusion in (5) is obviously valid. So, an attempt to resist the conclusion must involve at least one of the following: the denial of premise (1), the denial of premise (3), the denial of premise (4) or the rejection of the inference from (1) to (2). In what follows, I argue first that, even if premise (1) as stated is false, it can survive in a modified form. Next, I demonstrate that the inference from (1) to (2) is in fact invalid, but not in a way that would enable Source Internalists to resist a modified version of the argument. Following that, I argue that, although premise (4) as stated is false, the argument can be run with a suitably modi-

8 Parfit (2011: 40).

9 Following Schroeder (2007), I will understand "desire" in this discussion as a kind of placeholder for whatever kind of mental state or states that the best version of internalism would hold to be normatively relevant.

10 Parfit (2011: 58-64).

11 Ibid.: 83. The final clause in the description is my own; it does not appear in Parfit's original case. Given his accompanying commentary on the case, though, it seems to me that Parfit would have no objection to the clause's inclusion. The discussion in $\ 5$, below, will make clear its significance. 
fied version of it, and that rejecting the modified premise is theoretically costly to Source Internalism. Finally, I argue that, although premise (3) is false, internalist attacks on the premise all fail. In order to cogently resist that premise, one must endorse Source Hybridism.

\section{Premise (1)}

Premise (1) tells us that:

If we have desire-based reasons for acting, all that would matter is whether some act would fulfill the telic desires that we now have after ideal deliberation. It would be irrelevant what we want, or would be trying to achieve.

The premise consists of two separate propositions. The first concerns what kinds of desires are reason-generating according to the best version of Source Internalism. The second has it that, however that class of desires is delineated, the actual content of one's duly purified desires does not make a difference for whether those desires can ground reasons. So, then, there are two ways to object to premise (1): deny the first of its claims, or deny the second.

Consider the first of the two claims. Ought we to deny it? While it may be right that Parfit has misidentified the class of desires that are most plausibly reason-generating, arguing for that does little to aid the internalist. ${ }^{2}$ This is because it is not enough for Parfit to have made that mistake - he must also have made it in such a way that it results in erroneously treating the desire of the agent in Case Two as reason-generating. That Parfit has made a mistake of that kind, though, is implausible. Parfit has already suggested a stringent restriction requirement: desires must be telic, and they must be such that they would survive, or be generated by, a kind of idealization process. The desire in Case Two meets these requirements, and it is not clear what kind of independently motivated additional requirement would rule it out. The most plausible additional requirement of which I am aware comes from Donald C. Hubin, who argues that desires can be reason-generating for an agent only if those desires are not in conflict with the agent's values. ${ }^{13}$ Hubin endorses that restriction because he is concerned with a certain kind of alienation that can sometimes occur between one's deepest commitments and one's desires. ${ }^{14}$ But adding Hubin's restriction to Parfit's preferred restrictions assists internalists only if it can explain why the desire in Case Two does not

12 For reasons to be suspicious of the delineation that Parfit proposes, see, for example, Gibbard (1990: 18-22); Loeb (1995); Rosati (1995); and Sobel (1994). While the discussions just cited are often more directly concerned with desire-based accounts of well-being rather than practical reasons, it should be clear how the criticisms of the former kind of view apply to the latter.

13 Hubin (2003).

14 Perhaps you think that such a possibility is ruled out by undergoing ideal deliberation. If that is so, then Hubin is not actually offering a requirement that, when combined with Parfit's, would result in requirements that are more restrictive. 
generate reasons for that agent, and it cannot do that. The agent in Case Two has a very odd kind of psychology; none of her aims or values conflicts with being in pain for its own sake. So the proposed additional restriction, even if adopted, does no work for the Source Internalist in resisting the All or None Argument. In short, modifying the first claim in premise (1) is helpful only if it makes premise (3) come out false, and no plausible modification seems capable of doing that.

A more robust defense of premise (1) might involve a discussion of many more proposals for restricting the class of reason-generating desires. While that kind of defense may be successful, it does not seem to me that it is necessary. That is because the proposed restriction on the kind of desires that can ground reasons, in order to avoid the difficulty for internalists raised by Case Two, must meet a difficult standard - namely, it must make it the case that it is impossible that the kind of desire that is reason-generating could have the content that the desire in Case Two has. Establishing that any plausible restriction would have that result will be extremely difficult. So, even if I have demonstrated only that denying the first part of premise (1) will probably not help the Source Internalist, I take it that the support for that demonstration is strong enough to establish a very significant argumentative burden for internalists who wish to take that route.

What of the second claim in premise (1)? Might Source Internalists attempt to deny that? Doing so would require arguing that certain desires cannot ground practical reasons because of the content of those desires. Opting for this response would, I think, be completely unmotivated, and deeply at odds with the spirit of Source Internalism. Internalism is partially motivated by the observation that each of us has reasons to do things that others lack, by virtue of desires that are not universally shared. Schroeder, for example, begins his investigation into practical reasons with a simple case:

Dance. Ronnie and Bradley have both been invited to a party. While Ronnie loves to dance and has a strong desire to do so, Bradley absolutely hates to dance, and desires not to do so. There will be dancing at the party. ${ }^{15}$

At the very heart of Source Internalism lies the intuition that Ronnie has some reason to attend the party, and that, whatever it is, it is a reason that Bradley lacks. Most plausibly, the internalist contends, that reason is best explained in virtue of some mental state that Ronnie has but Bradley does not. But the internalist does not insist that what explains Ronnie's reason is that the mental state's object has something to do with dancing. Rather, the thought is that the kind of mental state involved is importantly related to other normatively relevant features - to an agent's ends, perhaps, or to her motivation, or possible motivation, for acting. ${ }^{16}$ Insisting that only desires with

15 Schroeder (2007).

16 For a recent defense of Source Internalism that relies on the relationship between desires and motivational states, see Goldman (2009; 2010). 
certain contents are reason-generating would be to abandon a thought that is central to internalism as a normative theory.

The prospects for resisting the All or None Argument by rejecting premise (1) are not promising. All internalists should agree that, whatever necessary and sufficient conditions there may be for a desire to be reasongenerating, they are purely formal conditions that make no reference to a desire's content.

\section{The First Inference}

In the second step of the All or None Argument, we are meant to infer from its first premise that either all fully informed telic desires give us practical reasons, or none of them do. One might attempt to resist the argument by insisting that this inference is invalid. How might one substantiate that charge?

First, notice that the claim in (2) is that all telic desires that we would have after ideal deliberation do give us reasons, and not the related, but distinct, claim that they can give us reasons. That all duly purified telic desires in fact do give us reasons is a position that Source Internalists should reject. Suppose, for example, that I have a telic desire to visit Seattle, and that that desire survives the relevant kind of idealization process. Does it follow that that desire must generate reasons for me? No, not if there is nothing that I can in fact do that would promote that desire's object. If I am confined to a tiny cell, powerless to escape, then my desire to visit Seattle gives me no reason to do anything, for there is nothing that I can do that will get me any closer to the satisfaction of that desire. ${ }^{17}$

Indeed, not only is this what internalists should say, but the best versions of the view will in fact be committed to it. Consider, for example, Schroeder's internalist thesis:

For $\mathrm{R}$ to be a reason for $X$ to do $A$ is for there to be some $p$ such that $X$ has a desire whose object is $p$, and the truth of $R$ is part of what explains why $X$ 's $\operatorname{doing} A$ promotes $p . " 18$

As I lie about in my cell, there simply is no action that I can perform that would promote my desire's object, and so no fact that could be part of what explains why some action I could take would so promote.

17 Recall that I said earlier that I wish to remain noncommittal about what kinds of proattitudes in particular can ground normative reasons. Which attitudes can do so may be relevant, though, in determining whether the kinds of examples I offer in this section are apt. For example, it is not unreasonable to think that undergoing ideal deliberation would extirpate an intention to do something that, given an agent's situation, cannot be done. However, I see no reason to think that undergoing ideal deliberation would eliminate any pro-attitude that an agent might have toward some object that cannot be achieved. I might be perfectly rational in hoping, wishing or desiring to be in Seattle, even if I know perfectly well that I just cannot get there.

18 Schroeder (2007). 
If the preceding example is not convincing, we might consider a different kind of case. Suppose I have a telic desire that survives ideal deliberation, but the object of that desire is logically impossible. For example, imagine that I have the desire to draw a triangle with four sides, or to cause my baseball glove to both exist and not exist. Even though that desire might be the kind of desire that could generate reasons, according to Source Internalists, it will not in fact generate any reasons because nothing I can do will make it any more likely that my desire is satisfied, let alone make it actually satisfied. In light of the two kinds of cases just discussed, (2) ought to be revised as follows:

(2') Either all deliberatively purified telic desires could give us reasons, or none of them could.

That revision, however, is completely unhelpful to the internalist who wishes to resist the conclusion of the All or None Argument. The agent in Case Two does not have a desire that is like my desire to visit Seattle or my desire to draw impossible objects; unlike me, the agent in Case Two is capable not only of doing something that promotes her desire to be in agony for its own sake, but also of doing something that actually satisfies that desire. ${ }^{19}$ So, although the inference from (1) to (2) is invalid, that feature of the All or None Argument is of no use to internalists hoping to undermine it.

Given the proposed revision to premise (2), it is very difficult to see how any Source Internalists could find fault with the inference from premise (1) to $\left(2^{\prime}\right)$. Doing so would require endorsing the position that a certain class of desires cannot ground reasons because of their content - a view that, as I discussed above, all Source Internalists will want to deny. So the inference from (1) to $\left(2^{\prime}\right)$ is secure, I think, because ( $\left.2^{\prime}\right)$ is mistaken only if the content of an agent's desire could itself be normatively relevant, which (1) rules out.

Before moving on, let us stop to note that the modification to (2) requires a corresponding modification to (3), resulting in ( $\left.3^{\prime}\right)$ :

If all such desires could give us reasons, our desires could give us decisive reasons to cause ourselves to be in agony for its own sake, to waste our lives, and to try to achieve countless other bad or worthless aims.

The modification is minor, and does not interfere with Parfit's original support for the premise. If situations like Case Two provide sufficient support for (3), then they will do the same for $\left(3^{\prime}\right)$, since the desires like those in Case Two are indeed desires that agents can effectively act to promote or realize.

19 Strictly speaking, promotion relates actions and the objects of desires, not desires themselves. However, the satisfaction relation does take a desire as one of its relata, and, given the similarity between the two, it is sometimes natural to speak in terms of an action promoting a desire, as when distinguishing it from satisfying that desire, as in the text above. Throughout, the reader should take any talk of promoting a desire to be shorthand for promoting the object of that desire. I say more about the promotion relation in $\int 6$, below. 


\section{Street on Premises (3') and (4)}

If I am right that premises (1) and (2'), and the inference between them, are secure from attack, then the Source Internalist is left with the option of denying either premise ( $3^{\prime}$ ) or premise (4) if she hopes to undermine the All or None Argument. I said above that the support behind these premises is due to reflection on a certain kind of case, of which Case Two is one example. So, in order to create problems for either premise (3) or (4), the internalist must argue either that we are somehow mistaken in our intuitions about these cases, or else that internalism, despite appearances, really can accommodate those intuitions. In recent work, Sharon Street has offered ways for the internalist to pursue each of these strategies. ${ }^{20}$ In this section, I discuss objections to both premises $\left(3^{\prime}\right)$ and (4) inspired from her work, before returning to another possible internalist objection to premise $\left(3^{\prime}\right)$ in the two following sections.

First, let us see how Street's work might point the way toward an objection to premise $\left(3^{\prime}\right) .{ }^{21}$ The key idea is that because being in agony necessarily involves negative attitudes toward some sensation, or possibly some proattitudes toward the cessation of some sensation, it may be that internalists can account for the position that the agent in Case Two does not have decisive reason to cause herself to be in agony for its own sake.

According to the model that both Street and Parfit endorse, to be in pain is not merely to experience some sensation. Additionally, being in pain requires disliking that sensation - what Parfit calls a hedonic disliking.22 On this account, pain is itself a complex state comprised by a sensation and a specific attitude, viz., the hedonic disliking of that sensation. Additionally, agents will sometimes have attitudes about those complex states - that is, agents will sometimes have meta-hedonic attitudes about pains.

Although most of us typically have a meta-hedonic aversion to pain, the agent in Case Two does not; rather, she has a meta-hedonic pro-attitude toward causing herself to be in severe pain. According to internalists, this generates a reason for her to cause that agony, if she can. However, given the understanding of pain that Parfit and Street are operating with, internalists may also be able to account for a countervailing reason. Being in agony, they think, will itself involve a negative attitude directed toward certain physical sensations, and it is perfectly plausible to think that that attitude will also generate a reason, but one that counts in the opposite direction. So the internalist might contend that the agent in Case Two has both some reason to cause

20 Street (2009).

21 To be clear, I don't think that Street actually explicitly offers the kind of objection that I discuss here. It is clear, though, how her discussion of cases involving pain might incline one to endorse the objection. See especially (2009: 288).

22 Parfit (2011: 53). 
herself to be in agony for its own sake, but also some reason not to do so, and Source Internalism itself leaves open which of those two reasons is decisive. So the case cannot, on its own, show that an agent will ever have decisive reason to cause herself to be in agony for its own sake. Therefore, premise $\left(3^{\prime}\right)$ is at least not sufficiently supported.

I think that this possible internalist approach to Case Two is not plausible, but I also think that, even if it were, premise $\left(3^{\prime}\right)$ could still be easily supported. First, it is not clear that, even on the view of pain that Street accepts, the agent in Case Two has some reason not to cause herself the agony. Prior to causing herself to be in agony, the agent has no negative attitudes at all toward her future episode of pain. Indeed, this is by stipulation, given the way that Parfit describes the case. What is correct is that, necessarily, once she is in pain, she will have a hedonic disliking of the associated sensations, and that that disliking is capable of generating a reason for her - in this case, a reason to discontinue the pain. But none of this provides the agent with a reason not to initiate the pain in the first place. So, despite an account of pain that essentially involves evaluative attitudes, Source Internalism entails that the agent in Case Two has decisive reason to cause herself to be in agony for its own sake. 23

Perhaps, though, some unexplored maneuver enables the internalist to handle the above response. So long as we adopt an account of pain that necessarily involves negative attitudes, we will have left room for the internalist to account for reasons that we might otherwise have thought she could not explain. Suppose we grant that the internalist can account for a reason for the agent in Case Two to avoid causing herself to be in agony, and that we further grant that that reason is decisive - does it follow that premise $\left(3^{\prime}\right)$ is inadequately supported? I do not think that it does. Recall that Case Two is merely one instance of a variety of cases that can be offered to support the premise. There is nothing about $\left(3^{\prime}\right)$ that requires that it be supported by examples that involve pain. Consider the following:

Starvation. Beatrice prefers a slim physique over any physique large enough to sustain her life. Her preference is telic, and survives ideal deliberation. Beatrice has no other desires that would be frustrated by causing herself to have a physique so slim,

23 Parfit is in agreement with this diagnosis (2011: 74-82). Though, as was helpfully pointed out to me by an anonymous referee, it seems that it is at least in principle open to the internalist to maintain that future desires generate present reasons in just the way that present desires do. I set this possibility aside for two reasons. First, although I will not argue for it here, it seems to me that the best version of internalism will not take on this commitment. I direct the reader to Heathwood (2011) for an excellent discussion of the issue. See also Nagel (1970, especially chs. 6 and 7), for related discussion. Second, as the continuing main text makes clear, $\left(3^{\prime}\right)$ can be supported without appeal to cases involving pain and its attending evaluative features. 
though Beatrice does have options available to her that would not cause her death. ${ }^{24}$

Beatrice prefers that she starve to death for the sake of a body of a certain shape. ${ }^{25}$ Unlike being in agony, the object of Beatrice's desire does not necessarily involve any evaluative attitudes, so the internalist strategy discussed above for defusing the threat posed by Case Two cannot be deployed against Starvation. If Source Internalism is true, then Beatrice has most reason to cause herself to starve for the sake of a trim figure.

Street agrees with that diagnosis of Starvation, but insists that the internalist's verdict about the case is the correct one. So, even though premise ( $\left.3^{\prime}\right)$ is adequately supported, at least by cases that do not involve pain, premise (4) is nevertheless false - according to Street, agents with sufficiently strange psychologies, like Beatrice, really do have most normative reason to behave in ways that seem objectionable to most: "if we take the time to imagine clearly what a genuinely ideally coherent anorexic would look like, it becomes intuitively plausible that she would have most reason to starve herself to death for the sake of a trim figure." ${ }_{26}$

Street's view is that, when considering cases like Starvation, the opponents of internalists have been failing to imagine them properly, and that if we were to imagine them more clearly, we would agree with the internalist's verdict. The key passage is worth examining in detail:

If one forces oneself to imagine what such a being [an ideally coherent anorexic] would actually have to look like, then I think one will either cease to have clear intuitions about the case, or else conclude that someone so clearheaded and impassioned in the pursuit of her goal might well have most normative reason to starve herself to death. "Go for it," we might say to her, after long talks with her in which we assured ourselves of her flawless consistency and lack of illusion about the nonnormative facts. "I guess you should do whatever floats your boat, if you really feel that strongly about it." Our attitude here might be much like the attitude many of us would take toward a person who knowingly accepts a tremendous risk of dying in order to have a shot at reaching the summit of K2. The ideally coherent anorexic's aesthetic is harder to relate to, no doubt, but it doesn't seem to be in a funda-

${ }^{24}$ The case is inspired by Gibbard (1990: 171). As with Case Two, I will say more about the final clause of the case in $\int 5$.

25 As Gibbard (1990) and Street (2009) both appropriately note, Beatrice is very unlike actual people who suffer from the eating disorder anorexia nervosa. My discussion of Beatrice and Starvation should in no way be taken as commentary on that disease, or on any actual individual suffering from it.

26 Street (2011: 277). Street is surely not the only internalist who would endorse such a strategy, and she is not the first to suggest something like it. Donald Hubin (1991), for example, argues that apparently strange desires like Beatrice's really do generate genuine normative reasons for them. Nevertheless, Street is an especially useful foil in this context because she is admirably clear about endorsing the all-things-considered strength of the verdict in premise (4). Interestingly, as will be evidenced later, I agree with the spirit of Hubin's project, despite thinking that agents like Beatrice cannot have most reason to follow through on their aims. 
mentally different category. On the contrary, we can imagine the ideally coherent anorexic thrilled by those brief moments of achieving the figure she regards as so beautiful in the same way that a climber might be thrilled by his brief moments on the summit of $\mathrm{K} 2$, even while knowing full well that the gathering storm means he won't make it back down alive. ${ }^{27}$

What should we make of these remarks?

Street offers a possible conversation that we might have with Beatrice, at the conclusion of which we are resigned to never convincing her from her aim, and to telling her that she should do as she pleases. But even if we agree that this is the correct way to respond to Beatrice, we need not thereby agree that Beatrice has most reason to starve herself to death. As Gibbard notes, it is one question whether the ideally coherent anorexic has most reason to starve herself to death for the sake of a slim physique, while it is another what I should do when confronted with such a person, including what I should say to her of her aims. It is not in general true that whenever I abandon hope of talking an agent out of carrying out some end of theirs that I thereby concede that that agent has most reason, or any reason at all, to pursue that end. So, even if Street is right that we would conduct our conversation with Beatrice in exactly the way that she imagines, it does not follow from that that Beatrice has most reason to do as she wants, or that we should be less confident in our judgment to the contrary. ${ }^{28}$

I also think that Street's appeal to the K2 example in the passage above is unhelpful; if it is convincing, it may be for reasons that do not apply in Starvation. First, Street says that the K2 mountaineer faces a tremendous risk of death if he attempts the climb. This is importantly unlike what Beatrice is faced with if she makes good on her desire, which is certain death. By hypothesis, Beatrice can achieve the figure she desires only by dying. Again, if the $\mathrm{K} 2$ example is convincing, it would presumably be less so if we were to stipulate that the mountaineer is guaranteed to die in his attempt.

A further reason to be dubious of whatever force the K2 example car-

27 Street (2011: 280).

28 Gibbard (1990) makes a similar point, though it is put in terms of whether the anorexic's behavior is rational, which I think confuses what is really at issue, namely, her reasons. See Gibbard (1990: 166).

An anonymous reviewer has suggested that my reply to Street, which appeals to the distinction between what we judge an agent to have reason to do and what we judge we have reason to do in responding to her, is not apt. That is so, on this line of thinking, because, in Street's imagining of the case, we make a claim about what Beatrice should do ("I guess you should do whatever floats your boat"), which appears to be a judgment about her reasons. What I mean to suggest, though, is that, even given the vivid imagining of the case that Street invites us to undertake, those with clear, non-internalist intuitions can quite reasonably be unmoved: while I do not think that Beatrice should do what floats her boat, I may, under certain circumstances, accept the reasonableness of saying to her that she should. This is meant only to cast doubt on Street's support for her claim at the beginning of the quoted passage: that a full imagining of the case will interfere with clear, non-internalist intuitions regarding it. 
ries is that the mountaineer's successful endeavor constitutes what most of us would consider an important achievement, whereas Beatrice's successful endeavor does not. This is not simply to repeat Street's point that, as a matter of fact, Beatrice's goal is "harder to relate to." Rather, the thought is that, whereas the mountaineer's undertaking presumably involves the deft use of certain cultivated skills and abilities - what we might think of as achievements - Beatrice's undertaking presumably does not. Additionally, it is not unreasonable to think that we value achievements, and that we are correct to do so. ${ }^{29}$ Street's contention, then, that the goals of Beatrice and the mountaineer are not different in kind is at least under-supported.

The previous two comments on the K2 case are meant to show that, on the assumption that we are inclined to think that the climber has most reason to attempt his fatal climb, it may nevertheless be the case that Beatrice does not have most reason to starve herself to death. However, my considered judgment is that we should not be so inclined by the K2 case to begin with. Beatrice and the mountaineer are both making a kind of mistake, although one that, given their psychologies, they cannot be expected to see: in relentlessly pursuing their passions, even to their deaths, they forego valuable options that would otherwise be open to them. Perhaps what Beatrice and the mountaineer have most reason to do is to cultivate new desires and interests, ones the pursuit of which will not cause their early demises. ${ }^{30}$

\section{Additional Remarks on Premise (4)}

Before moving on to further discussion of premise (3'), I want to draw attention to three more points about premise (4). First, it might be thought that Source Externalists, like Parfit, cannot rely on such a premise when arguing against internalism because doing so begs the question against internalists. This is not so. To assume that the agent in Case Two does not have decisive reason to cause herself to be in agony for its own sake, or to maintain that Beatrice does not have decisive reason to starve herself to death in pursuit of some body shape, is not to assume any particular theory of the grounding of normative reasons that explains those facts. It is simply to start with an extremely plausible intuition about a case, and to test competing theories in light of it. It is not as though being committed to a verdict about Case Two or

${ }^{29}$ For a sample of recent discussions of the relationship between achievements and value, see Blaauw (2008), Bradford (2012), James (2005), Keller (2004), McNaughton and Rawling (2001), Portmore (2007) and Whiting (2012). As is made clear below, my final assessment of the K2 case does not depend on the success of any argument to the conclusion that achievements are valuable.

30 If I am right, as I speculated in n. 23, that the best version of Source Internalism will recognize the import only of present desires, then, on such a view, Beatrice and the mountaineer have no reason at all to replace their potentially fatal desires with those the pursuit of which would not jeopardize their health or lives, even if that could be accomplished as easily as is possible. That seems implausible, though I will not pursue this possible line of argument further. 
Starvation just is being committed to externalism, or even to the falsity of internalism.

Additionally, Source Internalists will agree that the kind of methodology just described is, in general, acceptable. As we have already seen, many internalists seek to restrict the class of desires that could be reason-generating. They do so because of intuitions about cases; they are trying to ensure that their theory is extensionally adequate, in the sense that it accurately captures our strongest pre-theoretical intuitions about certain cases. Pointing out that the best version of their theory fails in this regard is not to beg the question; it is to demonstrate that a theoretical virtue that they hope to secure for themselves is instead out of reach. ${ }^{31}$

My second observation about premise (4) is this: it is important to realize that, in defending the position that the agent in Case Two does not have decisive reason to cause herself agony for its own sake, one leaves open the possibility that that agent has some reason to do so, and similarly for related cases, like Starvation. The distinction is important. I argue below that the All or None Argument can be rejected by Source Hybridists because premise (3') is false. A natural strategy for dealing with attacks on that premise is to weaken it to $\left(3^{*}\right)$ :

If all such [deliberatively purified telic] desires could give us reasons, our desires could give us reasons to cause ourselves to be in agony for its own sake, to waste our lives, and to try to achieve countless other bad or worthless aims.

$\left(3^{*}\right)$ differs from ( $\left.3^{\prime}\right)$ only by dropping the word "decisive." With this modification in place, advancing the All or None Argument would require claiming in a modified premise (4) - call it $\left(4^{*}\right)$ - that we could not have any reason at all, decisive or otherwise, to do the sorts of things mentioned in premise $\left(3^{*}\right)$.

Although $\left(3^{*}\right)$ is true, $\left(4^{*}\right)$ is not. Beatrice does have some reason to cause herself to have a fatally slim physique for its own sake. To see that this is so, suppose that Beatrice is forced into an odd sort of choice situation: she can choose to starve herself to death, or she can choose to die in some alternative way that is equally bad for her, but, unlike her first option, will not involve bringing about her fatally slim physique. In this sort of case, one in which her options are otherwise equally choice-worthy, it does seem right that Beatrice's preference somehow results in her having more reason to choose the first option. ${ }^{32}$ And, if she has more reason to choose that way, then she must have some reason to. So, premise $\left(4^{*}\right)$ is false. ${ }^{33}$

${ }^{31}$ I say a bit more about this in the concluding section of the paper, $\int 9$.

32 If you are worried that Beatrice's desire makes her preferred option more valuable for her in some way, then let us imagine that the alternative method of dying is correspondingly slightly better than starving to death otherwise would be.

33 See Schroeder (2007: 84-102) for a similar argumentative strategy, and for further reason to give careful attention to our initial intuitions regarding negative existential claims about reasons. 
The foregoing comments require a third, and final, clarification about the precision and argumentative import of premise (4). ${ }^{34}$ I have said that, if her choice situation is restricted such that she cannot avoid dying in some way that is equally as bad as starving herself to death, Beatrice has most reason to follow through on her desire. While that point serves my purpose in demonstrating that adverting to the weakened $\left(3^{*}\right)$ is of no help in rescuing the All or None Argument from an attack on the original premise (3), the same point also demonstrates that premise (4) is, after all, false. In our reimagined version of Beatrice's case - call it Starvation 2 - Beatrice has decisive reason to pursue some deeply disvaluable end for its own sake. Premise (4) holds that this result is not possible, and so must be mistaken.

What is the import of this discovery about premise (4)? Does it show that internalists are, in the end, capable of resisting the All or None Argument? It does not. Even though (4) as stated is false, as evidenced by cases like Starvation 2, this does nothing to aid internalists in addressing the less complicated versions of the relevant cases, like Starvation and Case Two, for example. Although Beatrice has most reason to follow through on her strange desire when her alternatives are just as disvaluable, she does not have decisive reason to do so when her alternatives are otherwise. If Source Internalism is true, though, Beatrice has most reason to starve herself to death (assuming that she's capable of doing so) whatever alternatives are available to her - a result that remains incredibly implausible, despite our intuitions regarding Starvation 2.

The foregoing suggests that the relevant parts of the All or None Argument might helpfully be modified in something like the following way:

$\left(3^{\prime \prime}\right)$ If all such desires could give us reasons, our desires could give us decisive reasons to cause ourselves to be in agony for its own sake, to waste our lives, and to try to achieve countless other bad or worthless aims, even in circumstances in which those kinds of results are avoidable.

$\left(4^{\prime \prime}\right)$ We could not have decisive reasons to cause ourselves to be in agony for its own sake, to waste our lives, or to try to achieve bad or worthless aims in circumstances in which those kinds of results are avoidable.

Two brief remarks about this possible modification are worth discussing before moving forward. First, I recognize that there are likely to be concerns about how to understand what kinds of results are avoidable for agents like Beatrice and the subject in Case Two, and their various iterations. My thought is that something along the following lines is the right way to proceed: when Beatrice acts on her desire in Starvation, a disvaluable outcome was avoidable for her because had she chosen to circumvent it, she would

34 I thank Michael Goldsby for urging me to address this idea. 
have. ${ }^{35}$ The same is not true of Beatrice in Starvation 2, who is externally constrained such that, no matter how she chooses, some extremely disvaluable fate will be visited upon her. ${ }^{36}$

Relatedly, and lastly, we should be careful not to place too much emphasis on whether the suggested modifications to (3') and (4) have been carried out perfectly well. At the end of the day, what matters is whether the proposed diagnoses of cases like Starvation and Starvation 2 are correct; the argumentative structure of the All or None Argument could be carried out perfectly well while making reference only to specific cases, foregoing altogether an appeal to a proposition like (4) that attempts to state some general truth about the possibility of certain kinds of reasons. ${ }^{37}$ And above, I have already tried to show that internalist responses to cases like Starvation should not shake the widely held conviction that agents in those sorts of cases do not have decisive reason to act on their desires. If my efforts were successful, then we should remain confident that internalists are faced with counterexamples, even if it is nonetheless difficult to state a general principle like (4) that attempts to account for the normative feature that gives those counterexamples their punch.

\section{Premise (3') and the Overdetermination Response}

I have tried above to show that objections to the All or None Argument that target premises (1), (2) and (4) do not succeed. If I was successful, then the only premise left to attack is $\left(3^{\prime}\right): 38$

If all such desires could give us reasons, our desires could give us decisive reasons to cause ourselves to be in agony for its own sake, to waste our lives, and to try to achieve countless other bad or worthless aims.

35 Clearly, the suggestion is inspired by classic approaches to accounting for the ability to do otherwise in the compatibilist tradition. See, for example, Ayer (1954: 15-23). Perhaps one of the more contemporary descendants of such an approach would do the trick as well.

36 It might be thought that Beatrice is also constrained in the original Starvation, on the grounds that her psychological profile results in a psychological, rather than external, constraint. I am inclined, though, to think that this is mistaken. The paradigm case of psychological constraint is the addict, who, however she wishes to act, finds herself compelled to act in accordance with her addiction. Supplement her with additional desires or choices to do otherwise, and the result remains the same - always she reaches for the cigarette, or slips the merchandise into her pocket without paying. But there is no reason, so far as I can see, to suppose that Beatrice and related possible agents are addicted to acting in accordance with their desires. Supplement Beatrice with some choice to do otherwise, and she will. I am willing to grant, though, that the circumstances under which Beatrice would choose to do otherwise are more modally "distant" than are similar choices of more normal agents, and that this may indicate a weakness in the approach for which I am advocating here.

${ }^{37}$ I am grateful to Michael Titelbaum for helping me to think about this point.

38 Or whatever version of $\left(3^{\prime \prime}\right)$ ends up being most satisfactory. Because I was somewhat noncommittal in $\int 5$ about how that updated version of the premise should be formulated, and because nothing I say in what follows depends on that modification, I focus on $\left(3^{\prime}\right)$. 
In my discussion of Street, I have already argued that one internalist attack on that premise fails. In this section and the following, I continue that work by arguing that a second, prominent internalist objection is also unsuccessful. Following that, I offer my own criticism of the premise, setting the stage for a limited defense of Source Hybridism.

We have already said above that it is implausible for Source Internalists to argue that $\left(3^{\prime}\right)$ is false on the grounds that, despite appearances, internalism is not committed to there being any reason for agents like Beatrice to act on their aberrant desires, let alone a decisive reason. A more promising line of attack against premise $\left(3^{\prime}\right)$ requires two steps. First, one must argue that, even if the agent in Case Two (and any agent in a similar sort of case) really does have some reason to cause herself to be in agony for its own sake (or whatever the relevant desired end may be), there is at least one additional reason for that agent not to do so. Second, one must also show that that additional (set of) reason(s) outweighs the agent's reason to cause herself to be in agony. Remember that Parfit's complaint is not that there is no reason at all for her to cause herself to be in agony for its own sake; rather, his complaint is that that reason cannot be decisive.

For the Source Internalist, discharging these argumentative burdens will first require explaining how there could be an internally sourced reason not to cause oneself to be in agony for its own sake, despite appearances to the contrary. So far as I know, the most sophisticated internalist attempt to show generally how internally sourced reasons can be found when they seem to be wanting is due to Schroeder. ${ }^{39}$ It will be instructive, then, to see whether Schroeder's strategy will be of assistance in an attempt to resist premise (3'). Thankfully, we will be able to set aside a discussion of whether internalists can discharge the second of the two argumentative burdens, for, as I will now argue, they cannot unburden themselves of the first.

The most difficult reasons for internalists to account for are those that are agent-neutral. Roughly, these are reasons for any agent, reasons that would remain even if that agent's set of desires were to change. ${ }^{40}$ An excellent candidate for such a reason is the one Parfit suggests in Case Two: that of avoiding escapable future agony. But the class of such reasons is typically thought to be much larger, including, for example, moral reasons, and perhaps a standing prudential reason to promote one's welfare. On the face of it, the difficulty for internalism is serious: internalists maintain that practical reasons are grounded exclusively in desires (again, understood broadly), so that which reasons an agent has will depend in some way on which desires she has. As a result, it would not be surprising if, according to this view, there are no rea-

${ }^{39}$ Schroeder (2007: 103-22).

40 There are much more precise ways of approaching agent-neutrality, but it does not seem to me that the details are relevant in this discussion. To understand how Schroeder, my primary interlocutor in this section, approaches the issue, see his (2007: 108-13). 
sons than an agent could have no matter what her desires.

Schroeder has argued, though, that internalists can go much further in accounting for agent-neutral reasons than previously thought, and that they can perhaps account for them entirely. To see how he does so, it will be useful to recall his analysis of practical reasons:

For $\mathrm{R}$ to be a reason for $X$ to do $A$ is for there to be some $p$ such that $X$ has a desire whose object is $p$, and the truth of $\mathrm{R}$ is part of what explains why $X$ 's $\operatorname{doing} A$ promotes $p \cdot{ }^{41}$

An important element of this analysis is the promotion relation, one in which actions stand to the objects of desires. The key to accounting for agentneutral reasons, Schroeder contends, is the weakness of the promotion relation. On his view, it is very easy for an action to promote the object of a desire. All that is required is that the action increases the likelihood of realizing or securing the desire's object relative to the agent's doing nothing at all. If an action makes a desired state of affairs even slightly more likely, then it will promote it, according to this picture. ${ }^{42}$

The weakness of the promotion relation is important for Schroeder in explaining why his "favored proposal for how there could be genuinely agent-neutral reasons is ... that genuinely agent-neutral reasons are massively overdetermined. They are reasons for anyone, no matter what she desires, simply because they can be explained by any (or virtually any) possible desire." ${ }^{43}$ The idea is that there will be some actions for which any agent would have a reason, regardless of her idiosyncratic desires, because so acting would promote any desire she had. That is a surprising position to take, but it is made more palatable by going in for an extremely weak account of the promotion relation; if it is easy for actions to promote desires, then it will thereby be easier to ground reasons for those actions in a wide variety of desires with differing contents.

The project here is ambitious. When applied to Parfit's Case Two, Schroeder's overdetermination response promises to find for us a reason for the agent not to cause herself to be in agony for its own sake, a reason that can be explained in terms of any of that agent's desires. The difficulty in making good on such a promise, though, should be obvious. Even if there are some actions that would promote almost all desires, it is straightforwardly not the case that the agent in Case Two has a desire that would be promoted by failing to cause herself to be in agony. Indeed, that feature of the case is simply stipulated.

Notice that there is nothing peculiar here about Case Two that renders

${ }^{41}$ Ibid.: 193.

42 Ibid.: 113. For additional discussion of the promotion relation, see Behrends and DiPaolo (2011; 2016), Coates (2014), DiPaolo and Behrends (2015), Evers (2009), Lin (forthcoming), Sharadin (2015) and Snedegar (2014).

43 Schroeder (2007: 109). 
Schroeder's overdetermination response impotent. For any putatively agentneutral reason, it is easy to imagine possible agents whose psychologies cannot ground those reasons, so long as we are willing to imagine agents with sufficiently strange desire sets. ${ }^{44}$ Notice also that weakening the promotion relation (supposing that it could be plausibly weakened any further than Schroeder's version of it) will be of no help. If an agent has a desire whose object is $p$, it is difficult to see how an internalist could argue that there is any fact that is part of what explains why that agent should $A$, when doing so would bring about not-p.

Even if ultimately unsuccessful for Schroeder's purposes, the overdetermination strategy contains much of interest. I agree with Schroeder that internalists are capable of demonstrating that many desires will generate far more reasons than they have typically been thought capable of, and it may even be right that, for most or even all actual agents, the overdetermination response is capable of explaining why those agents have reasons not to cause themselves harm for its own sake, or why they have reason to act morally, regardless of their idiosyncratic desire sets. But our normative theory of reasons should apply not only to all actual agents, but to all possible agents, for the true normative theory is presumably necessarily true. ${ }^{45}$ But the agent in Case Two is a possible agent; so, to the extent that Source Internalism cannot account for a reason in that case that all possible agents should have, we have reason to be suspicious of internalism.

\section{The Overdetermination Response Plus the Velleman Hypothesis?}

Schroeder is not unaware of the kind of difficulty just canvassed, and he is now apparently sympathetic to a kind of response to that difficulty that is inspired by the work of David Velleman. I said above that the overdetermination response fails because agents like the agent in Case Two are possible, and that Schroeder's account cannot explain how agents of that kind have the reasons that we think they do. Schroeder now believes, I think, that that claim is false, because the putative agents in question are in fact not agents at all. 46

Why think that the apparent agent in Case Two is no agent at all? The idea is that there is a certain desire, or set of desires, that is constitutive of agency, such that if some being fails to have that desire or that set of desires then that being is not an agent. That idea is what Schroeder refers to as the Velleman bypothesis, for Velleman's influential defense of the position. ${ }^{47}$ If the

${ }^{44}$ For a more extended treatment of this problem, see Shafer-Landau (2012). For related discussion, see also McPherson (2012) and Lin (2015).

${ }^{45}$ For further defense of relying on cases involving subjects with psychologies that are radically different from our own, see Street (2009).

${ }^{46}$ Schroeder (2012: 468-69).

${ }^{47}$ For Schroeder's initial discussion of the Velleman hypothesis, in which he expresses skepticism about the position, see Schroeder (2007: 107). For his later, more sympathetic take, 
Velleman hypothesis is correct, then Source Internalists can deflect seeming counterexamples like Case Two on the grounds that the beings in those cases are not agents, because they lack the relevant desire or set of desires, and so could not have practical reasons of any kind, let alone the reasons that are supposed to be difficult for Source Internalists to account for. Internalists taking this line will happily admit that the being in Case Two does not have a reason to avoid causing herself agony for its own sake, but that is simply because, according to them, that being is not the sort of thing that could have reasons at all.

Suppose that it is right that there is some desire that is constitutive of agency, and that the being in Case Two lacks it. Even so, the Source Internalist is faced with at least two challenges that must be met before it can be shown that the marriage of internalism and the Velleman hypothesis can help the internalist to reject premise ( $3^{\prime}$ ) of the All or None Argument. First, the internalist must specify which desire is constitutive of agency, and give an adequate defense of that position. Additionally, though, the internalist must show that if the near-agent in Case Two had whatever desire is thought to be constitutive of agency, then she would have a reason not to cause herself to be in agony for its own sake. Indeed, the internalist would need to show that such a strategy will be successful in every case that is relevantly like Case Two, including, for example, Starvation.

Concentrating on the first of those tasks would, I think, take us very far afield. Velleman himself has defended throughout his career inconsistent accounts of which desire is constitutive of agency, and some of his work on the matter, by his own admission, is murky.48 But we need not wade deeply into those muddy waters so long as we can show that it is extremely unlikely that any desire that is plausibly thought of as constitutive of agency could do the work that Source Internalists would need for it to do.

Constitutivists of Velleman's stripe contend that there is some desire such that, if a being lacks that desire, then its behavior cannot properly be thought of as acting. The idea is that, if a being cannot act, then the reason relation will not apply, as the relation is one that obtains among agents, facts and actions. This contention serves as a kind of constraint on the possible content of a desire that is plausibly constitutive of being an agent. No one could reasonably insist, for example, that I do not really count as acting if I do not have as one of my aims or goals the acquisition of baseball cards. That is presumably because the acquisition of baseball cards is wholly unrelated to action as such. So desires that have a close relationship to action as such must have fairly general content, lest they be the kind of desire of which we could legitimately ask, "Why must I care about that in order to count as an agent?”

see Schroeder (2012: 468-69). For the most relevant of Velleman's writing, see Velleman (2000: 1-31 and 170-99; 2004).

48 Velleman (2004: 236). 
There may indeed be desires that do not run afoul of the constraint just discussed; I intend to remain neutral on that point here. Velleman has at different times suggested that, necessarily, agents desire autonomy, or a kind of self-understanding. Kieran Setiya defends a position similar to the view found in Velleman's later work, according to which agents act with the aim of self-knowledge. ${ }^{49}$ But supplementing the supposed agent in Case Two with any of these desires will simply not generate for her a decisive reason not to cause herself to be in agony for its own sake; at any rate, it would take an $e x-$ traordinary amount of argumentation to show how it could. Worse, as the Case Two subject presumably intends to cause herself to be in agony for its own sake, acting otherwise would presumably frustrate her desire for autonomy, or self-understanding, or self-knowledge. If that is so, then not only would supplying that subject with one of these desires fail to generate for her a reason to refrain from acting as she wishes, but it also would apparently be capable of grounding an additional reason so to act. ${ }^{50}$

Recall also that Case Two is not the only scenario in which we tend to think that there are agent-neutral reasons that Source Internalists cannot capture. So even if the desire that is constitutive of agency could ground a decisive reason in that case, it would also need to do so in every other problematic case. Consider Beatrice again. Suppose that, in addition to caring about her physique, she also has a desire for autonomy. That desire seems to ground a reason for her to pursue her favored physique, as she will thereby be autonomously acting on some value or principle that she endorses. A desire for self-understanding seems to do the same; she will fail to make sense to herself if she fails to act on the value that she holds dearest.

The difficulty with a constitutivist attack on premise $\left(3^{\prime}\right)$ is that any plausible candidate for a desire that is constitutive of agency must be sufficiently general, lest it rule out subjects that otherwise seem just like agents. But those sorts of desires, when added to a desire set that is like Beatrice's, for example, are not substantive enough to ground reasons that countermand those grounded by the subject's other desires. Indeed, the candidate desires that have so far been proposed seem rather to ground reasons that supplement those other reasons.

\section{The Hybridist Rejection of Premise (3')}

I have so far canvassed what I take to be all of the plausible responses to the All or None Argument that are available to internalists, and found them wanting. Nevertheless, I think that the argument is unsound, because premise $\left(3^{\prime}\right)$ is false.

49 Setiya (2003). It is interesting to note that, although Setiya thinks that there is a desire or aim that is constitutive of agency, he explicitly denies that that desire can ground practical reasons in the way that an internalist might hope that it can.

50 Lin (2015) raises a similar concern. 
The idea behind premise $\left(3^{\prime}\right)$ is that if all deliberatively purified telic desires could be reason-providing, then it would be possible that an agent could have decisive reason to do something really terrible, such as waste her life. So, in order to create problems for premise $\left(3^{\prime}\right)$, we need to be able to show that the truth of the antecedent is compatible with the impossibility of an agent's having decisive reason to do such things. Suppose the world of reasons looks roughly like this: some normative reasons for actions are generated by desires in just the way that Parfit's Source Internalists maintain; telic desires that agents have after ideal deliberation are always reason-generating. Additionally, though, normative reasons for action are also grounded in just the way that Source Externalists maintain; either there are brutely normative facts, or else some facts derive their normative force in virtue of a relation in which they stand with facts about value. The position that some, but not all, practical reasons are internally sourced, and that some, but not all, practical reasons are externally sourced is Source Hybridism.

Now consider the agent in Case Two. If Source Hybridism is correct, then the agent in this case has both a desire-given reason to cause herself to be in agony, and, we can safely assume, a value-based or brute reason not to cause herself to be in agony. The assumption here is substantive, because neither Source Externalism nor Source Hybridism is committed to any particular first-order conception of reasons. However, the assumption is safe, I think: if we are already convinced that the agent in Case Two does not have decisive reason to cause herself to be in agony for its own sake, and if the previous arguments show that internalists cannot account for that, then we must think that there is some externally sourced reason or other that yields such a result. Presumably, that reason is somehow related to the badness of being in agony.

The mere possibility of Source Hybridism's truth, combined with its ability to generate conflicting reasons for the agent in Case Two, does not show that premise $\left(3^{\prime}\right)$ is false. Even if hybridism as so far described is true, we have not yet seen any reason to think that the existence of countervailing externally sourced reasons would render it impossible for an agent to have decisive reason to cause herself to be in agony for its own sake. That is because our hybrid picture has not yet been filled in with a description of how internally and externally sourced reasons relate to each other. In particular, we have not seen an explanation of how the two kinds of reasons are to be weighted.

Fortunately, as I have argued elsewhere, we should be confident that there is a good account of normative weighting that entails that the externally sourced reason to avoid agony in Case Two must outweigh the internally sourced reason to cause agony. ${ }^{51}$ In short, the idea is that, if we can take standard intuitions about Case Two and its close relatives seriously when thinking about the grounding of reasons, then we can also take them serious-

51 Behrends (2015). 
ly when thinking about a theory of normative weight. So, any theory of weighting that does not entail that the agent in Case Two has most reason to avoid causing herself to be in agony for its own sake should be rejected for precisely the same reason that Source Internalism should be rejected: it is extensionally inadequate.

So we should conclude that premise $\left(3^{\prime}\right)$ is false. That all desires of a certain sort could ground reasons for action does not suffice for it being the case that agents could have decisive reasons to do terribly disvaluable things, because those agents may have countervailing and outweighing reasons that are not internally grounded. So, if one is attracted to the idea that at least some reasons are grounded internally, one can resist the All or None Argument by endorsing Source Hybridism.

\section{Taking Stock}

There is much more to be said about hybridism, both with respect to weighting and to other possible complications the view may face. ${ }^{52}$ And I want to be clear that I do not think that the arguments I have marshalled here are capable of showing that Source Hybridism has a decisive advantage over Source Internalism. For all that I said in $\int 5$, it is open to internalists to insist that (4) should be rejected not on extensional grounds, but in light of further theoretical considerations. The arguments here leave open the possibility that Source Internalism pays a cost with respect to extensional adequacy, but that that cost is compensated for elsewhere.

What I hope to have established is that Source Hybridism enjoys at least a very significant prima facie advantage over Source Internalism, so far as pre-theoretical extensional adequacy is concerned: it does not lead to objectionable verdicts about scenarios like Case Two, Starvation and similarly constructed cases. Further, Source Hybridism offers a way to accept the force of the kinds of arguments that Parfit levels, while simultaneously holding on to a core normative insight of Source Internalism. For it does seem correct that desires are normatively relevant, and I am inclined to think that they are relevant in exactly the way that internalists take them to be. The flaw in Source Internalism is in thinking that all practical reasons are related to desires in that way. ${ }^{53}$

52 I address what I take to be the most significant objections in my (2015).

53 This paper has undergone several transformations since its original writing, and I have benefited enormously from many sources of feedback. Sarah Paul, Gina Schouten, Russ Shafer-Landau and Michael Titelbaum deserve special recognition for reading and commenting on the earliest drafts. Many of the ideas in this paper, in some form or other, were presented to the following conferences and departments, whose audiences I thank: the Midsouth Philosophy Conference (2012), the Central States Philosophical Association (2012), the American Philosophical Association (Eastern Division, 2012), the University of Wisconsin-Madison Department of Philosophy, the Illinois State University Department of Philosophy and the Concordia University (Montreal) Department of Philosophy. I thank also David Anderson, Chris Horvath, Gina Schouten and especially David Sanson for their attention 
Jeff Behrends

Harvard University

Department of Philosophy

jbehrends@fas.harvard.edu

to a later draft of the paper in our faculty reading group at Illinois State. Finally, I am grateful to two anonymous referees for this journal for their helpful criticisms and recommendations. 


\section{References}

Ayer, A. J. (1954) "Freedom and Necessity," in G. Watson, ed., Free Will, New York: Oxford University Press.

Behrends, J. (2015) "Problems and Solutions for a Hybrid Approach to Grounding Practical Normativity," Canadian Journal of Philosophy 45(2): 159-78.

and DiPaolo, J. (2011) "Finlay and Schroeder on Promoting a Desire," Journal of Ethics and Social Philosophy: 1-7.

(2016) "Probabilistic Promotion Revisited," Philosophical Studies 173(7): 1735-54.

Blaauw, M. (2008) "Epistemic Value, Achievements, and Questions," Proceedings of the Aristotelian Society, Supplementary Volumes 82(1): 43-57.

Bradford, G. (2012) “The Value of Achievements," Pacific Philosophical Quarterly 93(4): 204-24.

Chang, R. (2013) "Grounding Practical Normativity: Going Hybrid," Philosophical Studies 164(1): 163-87.

(2012a) "Commitment, Reasons, and the Will," in R. Shafer-Landau, ed., Oxford Studies in Metaethics, Vol. 8, Oxford: Oxford University Press, pp. 74-113.

(2012b) “Are Hard Choices Cases of Incomparability?” Philosophical Issues 22(1): 106-26. (2009) "Voluntarist Reasons and the Sources of Normativity," in D. Sobel and S. Wall, eds., Practical Reason and Action, Cambridge: Cambridge University Press, pp. 243-71.

Coates, D. J. (2014) “An Actual-Sequence Theory of Promotion," Journal of Ethics and Social Philosophy: 1-8.

DiPaolo, J. and Behrends, J. (2015) "Reason to Promotion Inferences," Journal of Ethics and Social Philosophy: 1-10.

Evers, D. (2009) "Humean Agent-Neutral Reasons?” Philosophical Explorations 12(1): 56-67.

Gibbard, A. (1990) Wise Choices, Apt Feelings, Cambridge, MA: Harvard University Press.

Heathwood, C. (2011) "Desire-Based Theories of Reasons, Pleasure, and Welfare," in R. Shafer-Landau, ed., Oxford Studies in Metaethics, Vol. 6, Oxford: Oxford University Press, pp. 79-106.

Hubin, D. C. (2003) "Desires, Whims and Values," The Journal of Ethics 7(3): 315-35. (1991) "Irrational Desires," Philosophical Studies 62(1): 23-44.

James, L. (2005) "Achievement and the Meaningfulness of Life," Philosophical Papers 34(3): 429-42.

Keller, S. (2004) "Welfare and the Achievement of Goals," Philosophical Studies 121(1): 27-41.

Lin, E. (forthcoming) "Simple Probabilistic Promotion," Philosophy and Phenomenological Research.

(2015) "Prudence, Morality, and the Humean Theory of Reasons," The Philosophical Quarterly 65(259): 220-40.

Loeb, D. (1995) "Full-Information Theories of the Good," Social Theory and Practice 21(1): 130.

Nagel, T. (1970) The Possibility of Altruism, Princeton: Princeton University Press.

McNaughton, D. and Rawling, P. (2001) "Achievement, Welfare, and Consequentialism," Analysis 61(2): 156-62.

McPherson, T. (2012) "Mark Schroeder's Hypotheticalism: Agent-Neutrality, Moral Epistemology, and Methodology," Philosophical Studies 157(3): 445-53.

Parfit, D. (2011) On What Matters, Oxford: Oxford University Press.

Paul, S. K. and Morton, J. M. (2014) "Of Reasons and Recognition," Analysis 74(2): 339-48.

Portmore, D. W. (2007) "Welfare, Achievement, and Self-Sacrifice," Journal of Ethics \& Social Philosopby 2(2): 1-28.

Rosati, C. (1995) "Persons, Perspectives, and Full Information Accounts of the Good," Ethics 105(2): 296-325.

Schroeder, M. (2012) "Reply to Shafer-Landau, McPherson, and Dancy," Philosophical Studies 157(3): 463-74. (2007) Slaves of the Passions. Oxford: Oxford University Press.

Setiya, K. (2003) "Explaining Action," The Philosophical Review 112(3): 339-93. 
Shafer-Landau, R. (2012) “Three Problems for Schroeder's Hypotheticalism," Philosophical Studies 157(3): 435-43.

Sharadin, N. (2015) "Problems for Pure Probabilism about Promotion (and a Disjunctive Alternative)," Philosophical Studies 172(5): 1371-86.

Snedegar, J. (2014) "Contrastive Reasons and Promotion," Ethics 125(1): 39-63.

Sobel, D. (1994) "Full Information Accounts of Well-Being," Ethics 104(4): 784-810.

Street, S. (2009) "In Defense of Future Tuesday Indifference: Ideally Coherent Eccentrics and the Contingency of What Matters," Philosophical Issues 19(1): 273-96.

Velleman, J. D. (2004) "Précis of The Possibility of Practical Reason," Philosophical Studies 121(3): 225-38.

(2000) The Possibility of Practical Reason, Oxford: Oxford University Press.

Whiting, D. (2012) “Epistemic Value and Achievement," Ratio 25(2): 216-30. 